\title{
Pengembangan Lampu Jalan Umum Dengan Listrik Tenaga Surya Di Desa Cilatak Kecamatan Ciomas Kabupaten Serang Banten
}

\author{
Andi Makkulau ${ }^{1}$; Rio Afrianda ${ }^{2}$; Kartika Tresya Mauriraya ${ }^{3}$; Nurmiati Pasra ${ }^{4}$ \\ 1, 2, 3,4 Teknik Elektro, Institut Teknologi PLN \\ ${ }^{1}$ andi.mk@itpln.ac.id
}

\begin{abstract}
Photovoltaic systems or solar power plants convert electromagnetic energy from sunlight into electrical energy. This renewable energy based power plant is one of the recommended solutions for electricity in remote rural areas where sunlight is abundant and fuel is difficult to obtain and relatively expensive. The Ministry of Energy and Mineral Resources has issued Ministerial Regulation regarding the use of the Roof Solar Power Plant system by consumers of the Indonesian Electricity Company (PLN). It is hoped that with this regulation the solar panel business and industry can flourish. The method we use in this Community Service is the observation method. By making observations in the field accompanied by interviews with the surrounding population becomes our primary data source in determining the needs of the problems that occur. In Cilatak Village we found minimal of street lighting, and limited electricity supply, for this reason we strongly support programs for new and renewable energy for remote areas that are difficult to get electricity supply. Based on this, we created the Development of Public Street Lights with Solar Electricity in Cilatak Village, Ciomas District, Serang District, Banten, so that the problems of public road lighting can be overcome, and we educated the utilization and maintenance.
\end{abstract}

Keywords: Public street lights, renerable energy, community service

\begin{abstract}
ABSTRAK
Sistem fotovoltaik atau pembangkit listrik tenaga surya (PLTS) mengubah energi elektromagnetik dari sinar matahari menjadi energi listrik. Pembangkit listrik berbasis energi terbarukan ini merupakan salah satu solusi yang direkomendasikan untuk listrik di daerah pedesaan terpencil di mana sinar matahari melimpah dan bahan bakar sulit didapat dan relatif mahal. Kementerian ESDM telah menerbitkan Peraturan tentang penggunaan sistem Pembangkit Listrik Tenaga Surya (PLTS) oleh konsumen Perusahaan Listrik Negara (PLN). Harapannya dengan aturan ini bisnis dan industri panel suraya bisa berkembang.Metode yang kami gunakan dalam Pengabdian Kepada Masyarakat kali ini adalah metode observasi. Dengan melakukan observasi di lapangan yang disertai dengan wawancara kepada penduduk sekitar menjadi sumber data primer dalam menentukan kebutuhan terhadap permasalahan yang terjadi. Di Desa Cilatak ditemukan Penerangan Jalan Umum (PJU) yang minim, dan pasokan listrik yang masih terbatas, untuk itu diperlukannya dukungan program untuk energi baru dan terbarukan untuk daerah - daerah terpencil yang sulit mendapatkan pasokan listrik. Berdasarkan hal tersebut peneliti membuat tim untuk pengabdian masyarakat dengan tema Pengembangan Lampu Jalan Umum Dengan Listrik Tenaga Surya Desa Cilatak Kecamatan Ciomas Kabupaten Serang Banten, sehingga masalah penerangan jalan umum dapat diatasi, dan kami melakukan edukasi pemanfaatan serta pemeliharaan tersebut.
\end{abstract}

Kata Kunci: PJU, energi baru dan terbarukan, Pengabdian masyarakat 


\section{PENDAHULUAN}

Kementerian ESDM telah menerbitkan Peraturan Menteri (Permen) Nomor 49 tahun 2018 tentang penggunaan sistem Pembangkit Listrik Tenaga Surya (PLTS) Atap oleh konsumen Perusahaan Listrik Negara (PLN). [1] Harapannya dengan aturan ini bisnis dan industri panel suraya bisa berkembang. Dalam beberapa tahun terakhir, Pembangkit Listrik tenaga Surya (PLTS) off-grid mengambil peranan penting dalam meningkatkan rasio elektrifikasi di daerah perdesaan di Indonesia.

Sistem PLTS terdiri dari modul fotovoltaik, solar charge controller atau inverter jaringan, baterai, inverter baterai, dan beberapa komponen pendukung lainnya. [2] Ada beberapa jenis sistem PLTS, baik untuk sistem yang tersambung ke jaringan listrik PLN (on-grid) maupun sistem PLTS yang berdiri sendiri atau tidak terhubung ke jaringan listrik PLN (off-grid). Meskipun sistem PLTS tersebar (SHS, solar home system) lebih umum digunakan karena relatif murah dan desainnya yang sederhana, saat ini PLTS terpusat dan PLTS hibrida (PLTS yang dikombinasikan dengan sumber energi lain seperti angin atau diesel) juga banyak diterapkan, yang bertujuan untuk mendapatkan daya dan penggunaan energi yang lebih tinggi serta mencapai keberlanjutan sistem yang lebih baik melalui kepemilikan secara kolektif (komunal). [3] Analisa situasi nya bahwa untuk daerah-daerah masih ada yang pasokan listik yang masih terbelakang mungkin dikarenakan Jaringan Distribusi yang sulit terjangkau dari PLN ke pelanggan (konsumen). [4]

\section{METODE / PERANCANGAN PENELITIAN}

Metode yang digunakan dalam Pengembangan Lampu Jalan Umum Dengan Listrik Tenaga Surya Desa Cilatak Kecamatan Ciomas Kabupaten Serang Banten ini adalah metode observasi. Dengan melakukan observasi di lapangan yang disertai dengan wawancara kepada penduduk sekitar menjadi sumber data primer dalam menentukan kebutuhan terhadap permasalahan yang terjadi. Tim peneliti mencoba mencoba mencari solusi dari permasalah listrik pada pasokan listrik desa tersebut dengan pemasangan dan Implementasi ke Lokasi desa tersebut berikut langkah - langkah yang akan kami lakukan:

1. Masyarakat diberikan informasi tentang Teknologi Listrik Tenaga Surya

2. Memasang Instalasi pada Lampu Jalan Umum dengan Teknologi Listrik Tenaga Surya

3. Menjelaskan sistem operasional untuk mesin pompa air di desa tersebut dan serah terima barang kepada Masyarakat Desa dengan diwakili pimpinan desa tersebut

4. Melakukan pengamatan, observasi dan wawancara untuk mengetahui dampak / hasil yang tampak saat pelaksanaan, dan dilanjutkan dengan laporan hasil pengamatan

5. Mengevaluasi hasil kegiatan pada masyarakat yang dilaksanakan

6. Membuat laporan pertanggung jawaban pelaksanaan kegiatan pengabdian pada masyarakat. 


\subsection{Diagram Alur Penelitian}

Pada penelitian ini diagram alur kerja penelitian dapat dilihat pada gambar 1. [5]

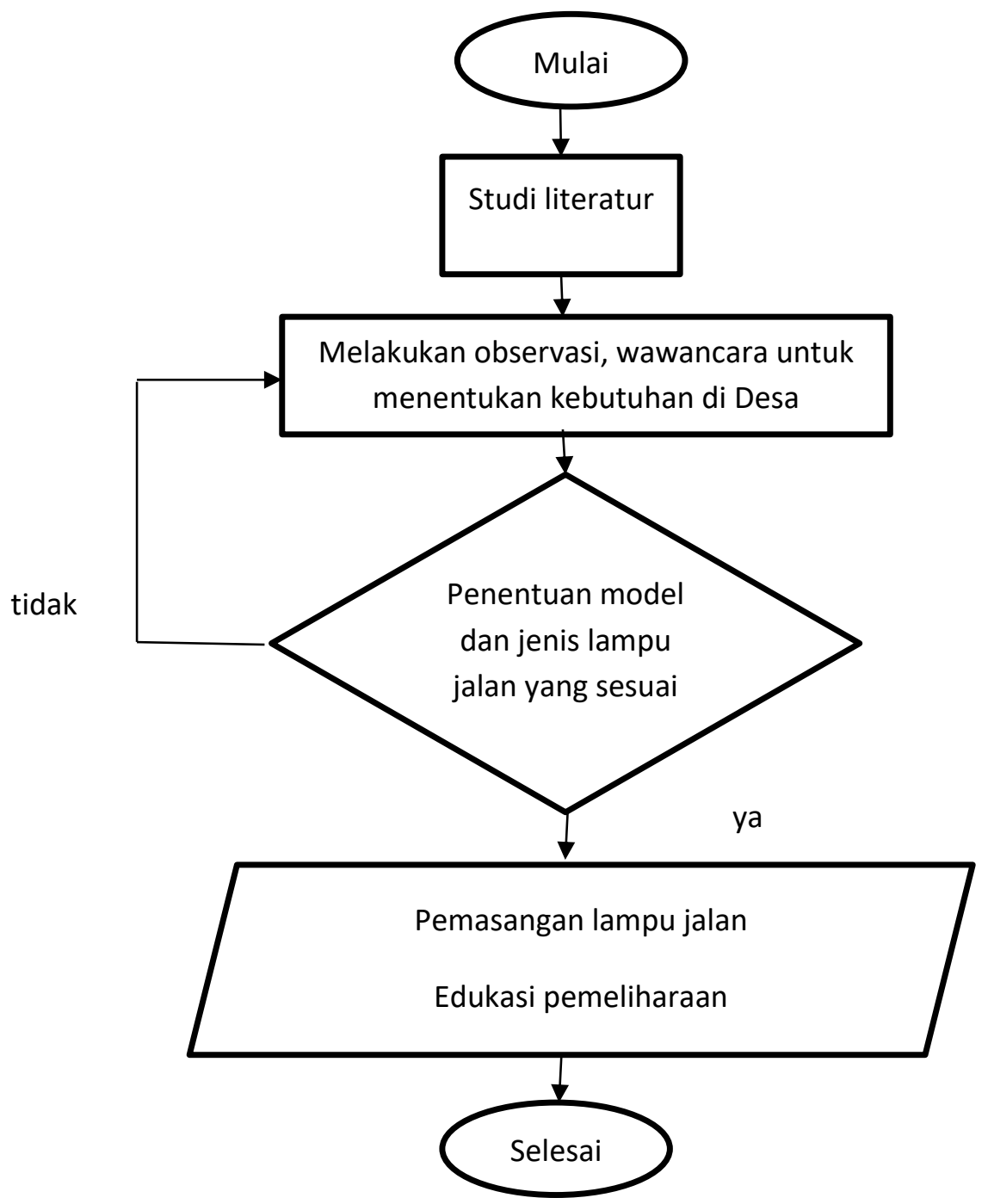

Gambar 1. Diagram Alir Penelitian

\subsection{Data Teknik Peralatan}

Modul Penerangan Jalan Umum tenaga Surya yang digunakan dalam P2M ini memiliki spesifikasi seperti yang ditunjukkan tabel 1 .

\section{SPESIFIKASI}

\begin{tabular}{ll}
\hline Daya & \multicolumn{1}{c}{$: 60$ Watt } \\
Garansi & $: 1$ tahun \\
Material & $:$ ABS \\
Warna Casing & \multicolumn{1}{c}{$:$ Grey Waterproof IP 65} \\
Ketinggian Optimal & $: 5-6$ Meter. \\
Batere & $:$ Lithium 3.7Volt / 9AH. \\
Waktu Charge Baterai $\quad: 8$ - 12 Jam (optimal). \\
Daya Panel Surya $\quad: 7 \mathrm{WP} / 6$ Volt.
\end{tabular}


Durasi menyala

Sensor

\begin{abstract}
: 9 Jam - 12 jam
: PIR Motion Sensor

Terdapat sensor cahaya yang dapat menyala otomatis ketika gelap (posisi ON), dan akan mati jika panel surya terkena sinar matahari. Terdapat PIR MOTION SENSOR, dimana lampu akan meredup jika sensor tidak menangkap pergerakan benda. Tetapi akan menyala $100 \%$ jika sensor menangkap pergerakan benda.
\end{abstract}

Tabel 1. Spesifikasi Modul Surya [2]

Berdasarkan analisis permasalahan mitra belum tersedianya sarana lampu penerangan jalan Desa dimalam hari, sehingga akan menyulitkan masyarakat atau warga desa jika ingin melakukan aktifitas dimalam hari. Ketersediaan pakar, dalam rangka mendapatkan solusi dari permasalahan mitra juga sangat diperlukan, jenis kepakaran yang diperlukan untuk melaksanakan kegiatan PkM edukasi pemanfaatan PLTS untuk Penerangan Jalan Umum adalah:

1. Pakar dalam Bidang Teknik Ketenagalistrikan (Elektro Arus Kuat)

2. Pakar dalam Bidang Teknik Elektronika

\section{HASIL DAN PEMBAHASAN}

Hasil Program kemitraan Masyarakat ini dapat membantu Desa Mitra dalam hal penerangan lampu jalan umum dengan menggunakan listrik tenaga surya. Karena, berdasarkan analisis situasi dan permasalahan mitra Desa Cilatak Kecamatan Ciomas Kabupaten Serang Banten, belum tersedianya sarana lampu penerangan jalan Desa dimalam hari, sehingga akan menyulitkan masyarakat atau warga desa jika ingin melakukan aktifitas dimalam hari. Kegiatan Program Kemitraan Masyarakat ini diawali dengan proses survei pada awal bulan November 2019. Dari hasil survei tersebut dan setelah mendapatkan persetujuan untuk melakukan pengabdian kepada masyarakat dengan tema "Pengembangan Lampu Jalan Umum dengan Listrik Tenaga Surya Desa Cilatak Kecamatan Ciomas Kabupaten Serang Banten" dan diikuti oleh segenap civitas dan masyarakat sekitar 40 orang yang dibuka oleh sambutan dari bapak RT. 06 Kelurahan Ciomas.

Tim PKM Institut Teknologi PLN memberikan edukasi singkat tentang pembangkit listrik tenaga surya sekala kecil yang dapat digunakan untuk lampu Penerangan Jalan Umum dan edukasi terkait perawatan / maintenance PJU yang telah dipasang. Dengan adanya kegiatan edukasi kepada masyarakat, akan membuka pola pikir masyarakat untuk menggunakan energi tepat guna sekala kecil yang ramah lingkungan dan sekaligus memberikan informasi berupa pengetahuan dan pemahaman mengenai pentingnya pemeliharaan secara berkala dari PLTS yang digunakan. 


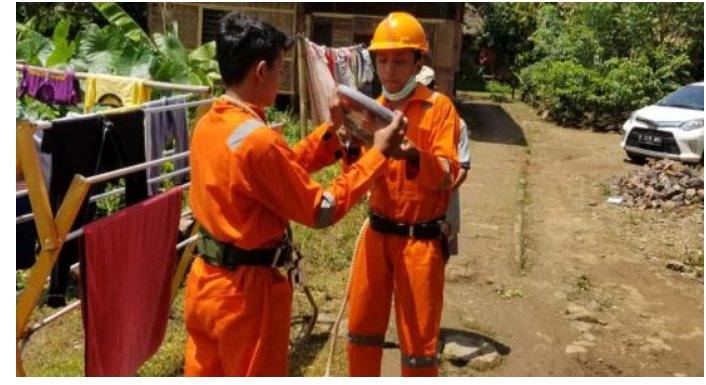

Gambar 2. Persiapan Pemasangan PJU

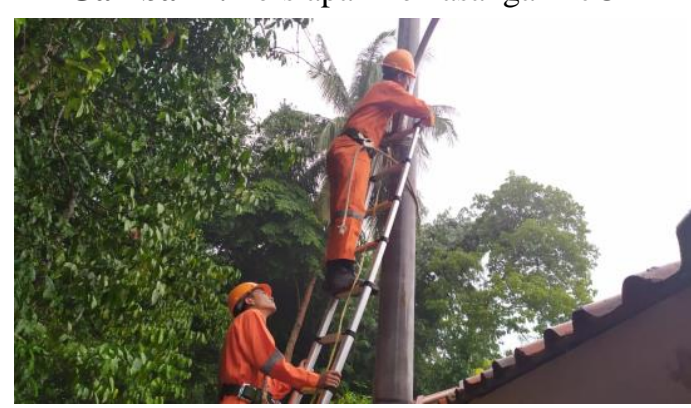

Gambar 4. Pemasangan PJU di Area Desa

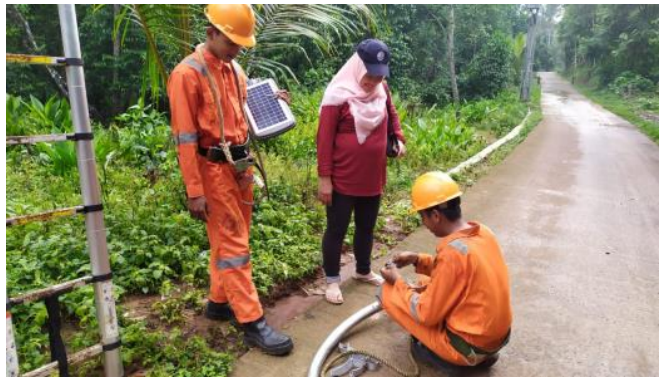

Gambar 3. Pemasangan PJU Titik Pertama

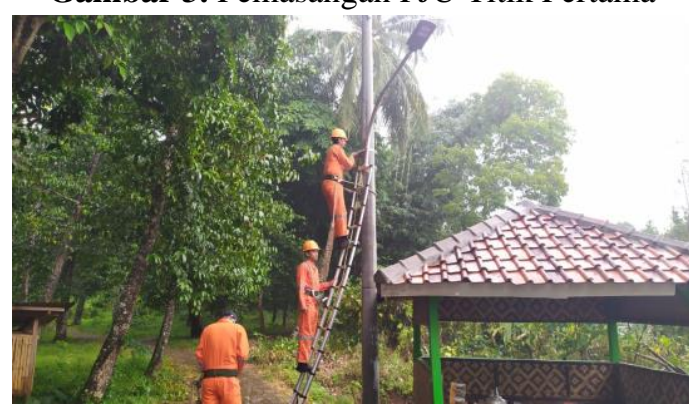

Gambar 5. Pemasangan PJU di area Musholla

Kegiatan Program Kemitraan Masyarakat Institut Teknologi PLN harapannya dapat terus terlaksana guna membantu Desa Mitra/ Binaan agar menjadi lebih baik dari sebelumnya. Kegiatan pengembangan lampu jalan umum dengan listrik tenaga surya desa Cilatak Kecamatan Ciomas Kabupaten Serang Banten seperti ini pada tahap berikutnya akan terus dilaksanakan baik itu di dalam lingkungan Institut Teknologi PLN itu sendiri maupun di luar lingkungan Institut Teknologi PLN, karena dari kegiatan seperti ini dapat memberikan manfaat yang besar terutama bagi masyarakat pada umumnya. Kegiatan seperti ini harus terus dilakukan terlebih karena saat ini pemafaatan energi baru terbarukan sangat penting untuk terus diupayakan. Kegiatan edukasi tentang pembangkit listrik tenaga surya berskala kecil yang dapat digunakan untuk lampu Penerangan Jalan Umum. Dengan adanya kegiatan edukasi kepada masyarakat, akan membuka pola pikir masyarakat untuk menggunakan energi tepat guna skala kecil yang ramah lingkungan dan sekaligus memberikan informasi berupa pengetahuan dan pemahaman mengenai pentingnya pemeliharaan secara berkala dari PLTS yang digunakan.

\section{KESIMPULAN DAN SARAN}

Pelaksanaan kegiatan ini mendapatkan dukungan dari pihak kelurahan Desa Sukadana Kabupaten Serang Banten karena melalui kegiatan ini segenap civitas dan warga masyarakat Desa Ciomas Desa Cilatak Kecamatan Ciomas Kabupaten Serang Banten. Dengan Adanya kegiatan Program Kemitraan Masyarakat ini, dapat dijadikan studi analisis terkait pemerataan listrik di daerah terpencil, beberapa hal yang kami temui Ketika melakukan kegiatan PkM ini yaitu belum tersedianya sarana lampu penerangan jalan Desa dimalam hari, sehingga akan menyulitkan masyarakat atau warga desa jika ingin melakukan aktifitas dimalam hari. Sehingga, melalui kegiatan PkM ini Institut Teknologi PLN dapat memberikan bantuan berupa fasilitas PJU untuk daerah yang masih minim penerangan.

Diharapkan kegiatan semacam ini diharapkan dilakukan kembali karena ini sangat bermanfaat untuk kita pada umumnya karena dapat memberikan pemahaman dan bekal ilmu kepada masyarakat mengenai penerapan energi tepat guna tepat guna skala kecil yang ramah lingkungan yang memanfaatkan energi matahari sebagai sumbernya. 


\section{UCAPAN TERIMAKASIH}

Penulis mengucapkan terima kasih kepada Institut Teknologi PLN melalui LPPM yang telah mendanai dan memberi dukungan yang membantu pelaksanaan P2M dan atau penulisan artikel ini.

\section{DAFTAR PUSTAKA}

[1] APAMSI, Pengembangan PLTS di Indonesia, Yogyakarta, 2013.

[2] K. H. Khwee, "Pengaruh Temperatur Terhadap Kapasitas Daya Panel Surya (Studi Kasus: Pontianak)," Jurnal ELKHA, no. 2 vol.5, 2013.

[3] A. Makkulau, Christiono and Samsurizal, "Characteristics of Temperature Changes Measurement on Photovoltaic Surfaces Against Quality of Output Current on Solar Power Plants," International Conference on Technologies and Policies in Electric Power \& Energy, IEEE, vol. doi: 10.1109/IEEECONF48524.2019.9102630., pp. 1-4, 2019.

[4] S. Makridakis, W. S.C, M. V and E. McGee, Metode dan Aplikasi Peramalan, Jakarta: Erlangga, 1999.

[5] Samsurizal, A. Makkulau and Christiono, "Analisis Pengaruh Sudut Kemiringan Terhadap Arus Keluaran Pada Photovoltaic Dengan Menggunakan Regretion Quadratic Method," Energi dan Kelistrikan, no. 2 vol.10 , pp. 137-144, 2018.

[7] Samsurizal, Christiono and A. Makkulau, "Evaluasi Sudut Kemiringan Terhadap Pengaruh Irradiance Pada Array Photovoltaic Jenis Monocristalline," Jurnal SETRUM, no. 1. vol.8, pp. 28-34, 2019.

[8] A. W. W. A. B. Duffie, Solar Engineering Of Thermal Processes, Newyork: John Wiley \& Sons, 2008.

[9] Sigiyono, Metode Penelitian Kuantitatif, Kualitatif dan R\&D, Bandung: Alfabeta, 2016. 